\title{
Umblical Endometriosis: Presentation of A Rare Case
}

\author{
Feyzi Kurt ${ }^{1^{*}}$, Cem Sezer ${ }^{2}$ \\ ${ }^{1}$ Department of General Surgery, Seyhan Public Hospital, Adana, Turkey \\ ${ }^{2}$ Department of General Surgery, Cukurova Public Hospital, Adana, Turkey
}

\begin{abstract}
Primary umblical endometrosis is a rarely seen entity. It consists of only $0.5-1 \%$ of extragenital endometrosis. Endometriosis may present in different regions with various clinical conditions. In this case report, a 45 years-old patient with an approximately $3 \mathrm{~cm}$ sized mobile, inflamed nodule with irregular appearance in umblicus which has cyclic umblical bloody discharge and pain during menstruation was underwent a total umblical excision. Cutaneous endometriosis was diagnosed as a result of the histopathological evaluation. With this case report, we want to emphasize that umblical endometriosis should be considered and taken in mind during evaluation of umblical nodule which lead to pain and bloody discharge from the umblicus with cyclic menstrual pain. And also, the diagnosis should be supported histopathologically after excision.
\end{abstract}

Key Words: endometrosis, umbilicus, cyclic menstrual pain

\section{Introduction}

Endometriosis is defined as the presence of endometrial glands and stroma in anatomic areas other than the uterus. Endometriosis is observed in the $6-10 \%$ of women who are at the reproductive age period and it causes infertility and pain in $35-50 \%$ of these women. Although it is frequently seen in pelvis; it has been identified in some cases with very rare locations such as umbilical region, subcutaneous connective tissue, skin, perineum and pleura (1). Umblical endometriosis has been observed often in patients undergoing laparoscopic surgery and it is reported that endometrial tissue inoculates after iatrogenic cause. Primary umblical endometriosis is a rare form of extragenital endometriosis which is accounted for approximately $0.1-1 \%$ of all cases.

Endometriosis may present in different locations with various clinical situations. These cases may apply to general surgery, plastic surgery, urology and gastroenterology clinics as well as applying to obstetrics and gynecology clinics. Radiological imaging holds limited place in the diagnosis of extragenital endometriosis. Diagnosis usually is made by pathologic examination after surgery (2).

We aimed to present a rare case of umbilical endometriosis with bloody umbilical discharge and pain.

\section{Case Report}

A forty five year old gravida 6, parity 6 patient admitted to our outpatient clinic with complaints of cyclic pain and bloody discharge in the umbilical area during menstrual period. Patient had regular menstruation on every 27 days lasting for 5 days. Patient had no history of dysmenorrhea, dyspareunia and pelvic pain. Her medical history did not have any history of trauma and umbilical surgery. On physical examination, approximately $3 \mathrm{~cm}$ in size mobile, irregular appearance of a inflamed nodule in umblicus was detected. Pelvic examination revealed a normal uterus and ovary with intrauterine device. On transvaginal ultrasound examination, a normal uterus with $6 \mathrm{~mm}$ of endometrial thickness and intracavitary located intrauterine device was detected. Two simple cysts with diameters of 20 and $30 \mathrm{~mm}$ were detected on bilateral ovaries. Uterine parenchyma was heterogeneous and there was intrauterine device material on the Computerized Tomography.

No pathologies were detected in other intraabdominal organs.

The patient was underwent to umblical mass excision under general anesthesia, the umblical nodule was resected with providing a at least $0.5 \mathrm{~cm}$ surrounding healthy tissue. (Fig. 1). Patient was discharged on the 3rd day post-operatively uneventfully.

Histopathological examination was reported as cutaneous endometrosis (Figure 2). On follow-up examinatons, the patient was free of symptoms and no recurrence was detected at 10 months after operation.

\section{Discussion}

Endometrosis is typically seen of the $10 \%$ of female population of reproductive age and usually seen in the 


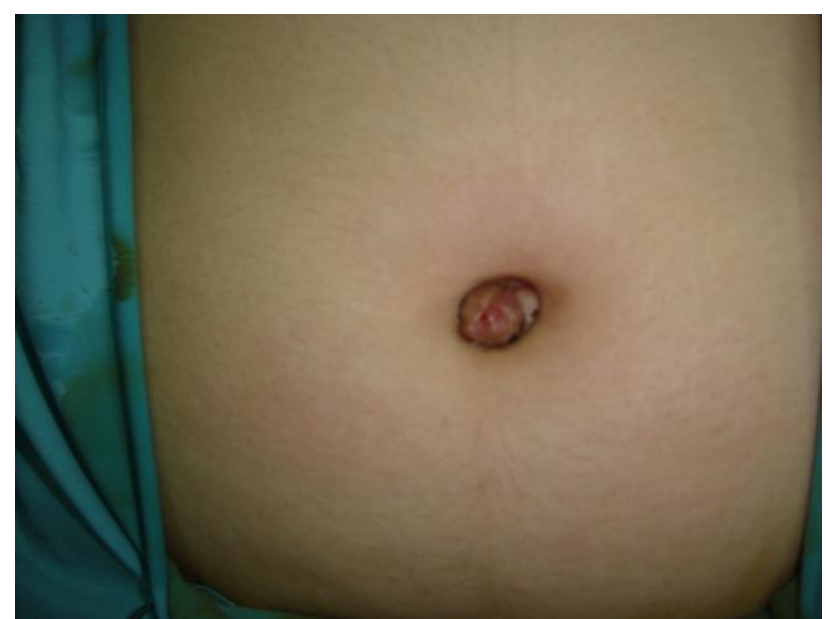

Fig. 1. Appearance of ectopic endometriosis in the patients abdomen

pelvic cavity. (3). Extragenital endometrosis is less than 1\% (4). Umbilical endometrosis described for the first time by Von Recklinghausen in 1885 (5).

Umbilical endometriosis can present with complaints of local pain, tenderness, and discoloration that can present in the form of masses during menstruation. Generally, a mass with 0.5 to $3 \mathrm{~cm}$ in diameter is palpated. Superficial ulceration and bleeding in lesions can be seen (6). In this case, we thought the umblical endometriosis due to the cyclic bloody discharge, pain and inflammed appearance with $3 \mathrm{~cm}$ diameter mass in umblical region as reported in the literature. Endometrosis develops in two mechanisms according to the etiology. Secondary endometrosis usually is developed after a surgical operation. It often occurs after a caesarean section and episiotomy repair (7). Primary, spontaneous endometrosis is not seen after a surgical procedure. Primary endometrosis is only 0.5 $1 \%$ of all endometrosis. Most commonly it is seen in the umbilicus (8). Rarely, secondary endometrosis are seen on umbilicus surgeries. In our case, due to the lack of a history of previous surgery or trauma it is considered as primary endometriosis.

According to the general popular view, the secondary endometrosis occurs due to the implantation of tissue in surgical incision. Based on another theory, endometrosis may develop upon proliferation of

other cells which transfer through the lymphatics (9). The general belief is that the development of endometriosis is multifactorial.

Umblical endometrosis is the form of $30 \%$ of the skin endometrosis. In $15 \%$ of those cases, there are also pelvic endometrosis (10). In our case, due to the lack of gynecological complaints, and a normal pelvic ultrasonography and CT image, abdominal exploration was not performed.

Excision is used widely for surgical treatment. However, danazol, a long-acting progesterone can be

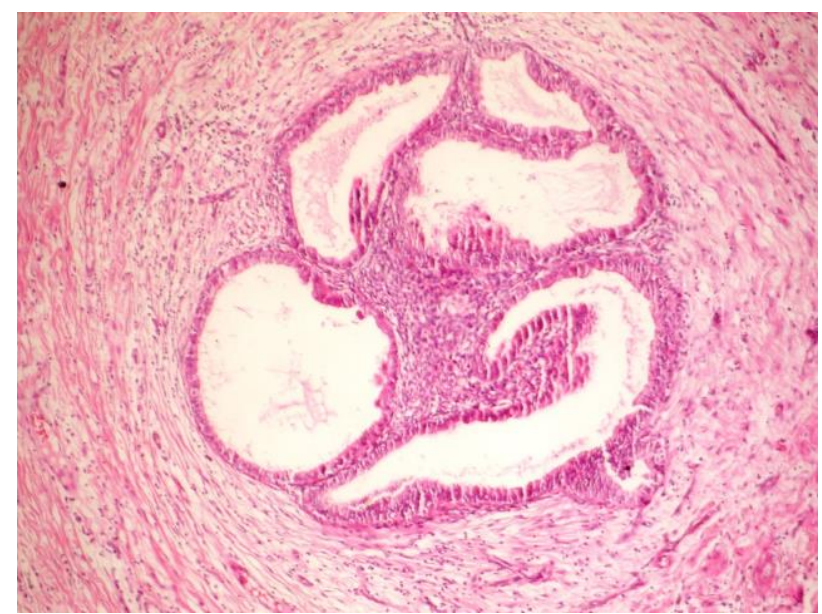

Fig. 2. Histopathological Appearance of endometriosis stained with hematoxylin eosin

used in cases that can not be totally excised and frequently recurred. GnRH analogues are also effective in preventing recurrence (11). We performed total excision of umblical nodule in our case. We did not apply any medical treatment on pre-operative and post-operative period. The differential diagnosis should include melanoma, primary or secondary carcinoma, hernia, keloid, and embryological remnants in these cases (12). The differential diagnosis should be made by histopathologic evaluation. In our case cutaneous endometriosis were confirmed as a result of histopathological evaluation.

The recurrence rate of extragenital endometriosis was reported to be $2-46 \%$. $27 \%$ of these cases underwent surgical treatment and $34 \%$ of cases were reported to underwent conservative approach. The possible prognosis is reported to be good in case of total excision especially in cases involving the skin and subcutaneous tissue (6). The endometriotic focus should be removed with a $5 \mathrm{~mm}$ in diameter surrounding the normal tissue in order to avoid the rupture or spillage of endometriotic tissue (13). A 0.5 $\mathrm{cm}$ solid tissue including umblicus in our patients was totally removed. No recurrence was detected on the 10th postoperative months follow-up examination.

Umbilical endometrosis is extremely rare. A cyclic pain and bloody discharge in umblicus during menstruation should prompt the diagnosis of umblical endometriosis. Total excision should be applied and the diagnosis should be confirmed with histopathologic examination.

\section{References}

1. Stepniewskal A, Grosso G, Molon A, et al. Ureteral endometriosis: clinical and radiological follow-up after laparoscopic 
ureterocystoneostomy. Human Reproduction 2011; 26: 112-116.

2. Yıldırım Y, Balsak D, Oktay M, Sönmez S, Tinar Ş. Malignensiyi Andıran Primer Abdominal Duvar Endometriyozisi: Eksizyon ve 'Polypropylene Mesh' Onarımı ile Tedavi Edilen Olgu. Balkan Medical Journal 2007; 24: 244-247.

3. Fernandez Vozmediano JM, Armario Hita JC, Cuevas Santos J. Cutaneous endometriosis and J. International Journal of Dermatology 2010; 49: 1410-1412.

4. Weed JC, Ray JE. Endometrosis of the bowel. Obstetrics and Gynecolgy 1987; 69: 727-730.

5. Demis J. Clinical Dermatology. Philadelphia Harper and Row Pub 1987; 4: 27-22.

6. Polat M, Karakaş K, Küçük M, Akdemir D. Umbilikal Endometriozis. Atatürk Üniversitesi Tip Bülteni 1992; 24: 5-9.

7. Purvis RS, Tyring SK. Cutaneous and subcutaneous endometriosis. Surgical and hormonal therapy. J Dermatol Surg Oncol 1994; 20: 693-695.

8. Von stemm AM, Mergel WN, Schidel P, Gocht A. Umblical endometriosis. J Eur Acad Dermatol venereol 1999; 12: 30-32.

9. Ichimiyo M, Hirota T, Muto M. Intra lymphotic embolic cells with cutaneous endometriosis in the umblicus. J Dermatol 1999; 25: 333-336.

10. Tidman Mj, Mac Donald DM. Cutaneous endometriosis a histopathologic study. J Am Acad Dermatol 1988; 18: 373-3777.

11. Agarwol A, Fong YF. Cutaneus endometriosis. Singapore Med J 2008; 49: 704-709.

12. Shachter LR, Tash J, Olgoc S, Bochner BH. Umblical endometriosis J Urol 2003; 170: 23882389.

13. Matthes G, Zabel DD, Nastala CL, Shestak KC. Endometrioma of the abdominal wall following combined abdominoplasty and hysterectomy: case report and review of the literature. Ann Plast Surg 1998; 40: 672-675. 